\title{
Vulnerabilidade socioespacial a secas e a inundações na Sub-bacia Hidrográfica do rio Piracuruca (Ceará-Piauí)
}

\section{Socioespatial vulnerability to droughts and floods in the Piracuruca River Sub-basin (Ceará-Piauí/Brazil)}

\author{
Francílio de Amorim dos Santos ${ }^{1}$ \\ Maria Lúcia Brito da Cruz $z^{2}$ \\ Lúcia Maria Silveira Mendes ${ }^{3}$
}

\section{Palavras-chave: \\ Desastres Naturais \\ Análise Fatorial \\ Análise de Componentes Principais \\ Criticidade \\ Capacidade de Suporte}

Resumo

Estudos voltados à compreensão da vulnerabilidade socioespacial, tendo a bacia hidrográfica como recorte espacial, são importantes para subsidiar o prognóstico e o planejamento frente à ocorrência de secas e inundações. Dessa forma, o objetivo da pesquisa foi analisar a vulnerabilidade socioespacial da Sub-bacia Hidrográfica do rio Piracuruca à ocorrência de secas e inundações. A Sub-bacia está localizada entre os estados do Ceará e do Piauí, drena uma área de $7.704 \mathrm{~km}^{2}$ e apresenta-se bastante heterogênea, tanto do ponto de vista biofísico quanto socioeconômico. Ao estudo foi aplicado modelo de estatística multivariada Análise Fatorial (AF) e método de estimação Análise das Componentes Principais (ACP), a partir do emprego de variáveis - demográficas, de infraestrutura, de saneamento básico, naturais, econômica e social da população - considerando os 296 (duzentos e noventa e seis) setores censitários, do censo demográfico de 2010. Destaca-se que a partir desse método/modelo e integração dos elementos Criticidade (características e comportamento da população) e Capacidade de Suporte (infraestrutura) foi possível a construção do índice de vulnerabilidade socioespacial (IVSE) da Sub-bacia do rio Piracuruca. Desse modo, as variáveis utilizadas para conhecimento da Criticidade apontaram que em $87 \quad(29,4 \%)$ setores da Sub-bacia predomina a classe alta. Por sua vez, inferiu-se por meio da Capacidade de Suporte que 137 (46,3\%) setores da Sub-bacia encontra-se na classe muito alta. Entretanto, o índice de vulnerabilidade socioespacial indicou a predominância da classe baixa, que se distribui por $172(58,1 \%)$ setores da Sub-bacia pesquisada.Contudo, é necessário realizar investimento para melhoria dos indicadores socioeconômicos e redução da Criticidade e manutenção da Capacidade de Suporte.

\footnotetext{
1'Instituto Federal do Piauí, Piripiri, Piauí, Brasil. E-mail: francilio.amorim@ifpi.edu.br 2Universidade Estadual do Ceará, Fortaleza, Ceará, Brasil. E-mail: mlbcruz@gmail.com 3Universidade Estadual do Ceará, Fortaleza, Ceará, Brasil. E-mail: lucia.mendes@uece.br
} 


\section{Keywords:}

Natural Disasters

Factor Analysis

Principal Component Analysis

Criticity

Supportability

\begin{abstract}
The relevance of studies aimed at the understanding of sociospatial vulnerability is emphasized, with the basin as a spatial cut-off, to support the prognosis and planning for droughts and floods. Thus, the objective of the research was to analyze the socio-spatial vulnerability of the Sub-basin of the Piracuruca River to the occurrence of droughts and floods. The sub-basin is located between the states of Ceará and Piauí, drains an area of $7,704 \mathrm{~km}^{2}$ and is very heterogeneous, both from a biophysical and socioeconomic point of view. The study was applied multivariate statistical model (FA) and method of estimation Principal Components Analysis (PCA), using variables - demographic, infrastructure, basic sanitation, natural, economic and social population - considering the 296 (two hundred and ninety-six) setore census, from the 2010 census. It is noteworthy that from this method / model and integration of the elements Criticity (characteristics and behavior of the population) and Support Capacity (infrastructure), it was possible to construct the SocioSpatial Vulnerability Index Sub-basin of the Piracuruca river. Thus, the variables used to know the Criticity indicated that in $87(29.4 \%)$ sectors of the Sub-basin predominate the upper class. In turn, it was inferred through the Capacity of Support that 137 $(46.3 \%)$ sectors of the Sub-basin are in the very high class. However, the socio-spatial vulnerability index indicated the predominance of the lower class, which is distributed by 172 (58.1\%) sectors of the sub-basin surveyed. However, it is necessary to invest in improving socioeconomic indicators and reducing Criticality and maintaining Support Capacity.
\end{abstract}

\section{INTRODUÇÃO}

De início, é relevante destacar que o Nordeste do Brasil exibe uma diversidade geoambiental marcada por uma condição de semiaridez, em $53 \%$ de sua área total, que resulta numa paisagem cujas precipitações são concentradas em curto período de tempo (SALES, 2002), fato que gera secas constantes e inundações periódicas, devido a irregular distribuição pluviométrica e, respectiva, concentração em curto período.

Deve-se ressaltar que a população que habita o semiárido tem ocupado essa região e buscado conviver com as secas e inundações. Posto que as secas e as inundações, historicamente, têm deixado grande número de pessoas desabrigadas e/ou desalojadas. Esses eventos extremos são classificados como desastres naturais e, para Marcelino (2008), têm acompanhado a história do homem e o modo como se apropria e usa os recursos naturais.

Destaca-se que, de acordo com o Anuário Brasileiro de Desastres Naturais (BRASIL, 2014, p.15), os desastres naturais são conceituados como sendo "[...] resultado de eventos adversos, naturais ou provocados pelo homem, sobre um cenário vulnerável, causando grave perturbação ao funcionamento de uma comunidade ou sociedade [...]”.

Os desastres naturais geram efeitos negativos quando manifestados em áreas habitadas, ao passo que mais de 130 milhões de latino-americanos vivem em situação de alto risco, conforme aponta o Sistema Económico Latinoamericano y del Caribe (SELA, 2011). Nesse cenário, Nunes (2015) reitera que as consequências negativas, fruto da manifestação de um desastre natural, podem estar mais ligadas às formas de ocupação do espaço geográfico que à magnitude do fenômeno.

Nesse sentido, afirma-se que o processo de segregação socioespacial acentua as consequências dos desastres naturais. Desse modo, Ramos (2003) diz que a segregação socioespacial está associada à forma desigual pela qual as classes sociais apropriam-se dos bens e serviços sociais, econômicos e culturais produzidos no espaço urbano. Lima (2001) afirma que a segregação relaciona-se à divisão da cidade em partes, promovento uma diferenciação econômica, social e psicológica que são reproduzidas espaço-temporalmente por meio 
das distintas formas de habitar.

Desse modo, ocorre a ocupação de espaços e implantação de equipamentos urbanos de forma diferenciada para atender seletivamente determinada classe social, tendo como foco a promoção da qualidade de vida. Nesse sentido, afirma-se que à segregação socioespacial está agregada a elementos inerentes à vulnerabilidade socioespacial que se interligam diretamente, notadamente pelo fato de que, geralmente, a população segregada é aquela que menos tem acesso aos instrumentos institucionais para melhoria da qualidade de vida.

Por vulnerabilidade, de acordo com Lavell (2010), entenda-se a predisposição ou propensão a elementos da sociedade de sofrer danos e perdas e encontrar dificuldades para recuperarse e, desse modo, conforme asseveram CamposVargas, Toscana-Aparicio e Alanís (2015), a vulnerabilidade determina a ocorrência e a intensidade dos desastres. Para Cunha et al. (2011), a vulnerabilidade expõe os indivíduos e bens, seu grau de resistência e de resiliência e comunidades à ocorrência de processos e eventos potencialmente danosos. Dessa forma, a vulnerabilidade agrega elementos associados à exposição e propensão ao risco (CUTTER, 2011).

Nesse contexto, insire-se a Sub-bacia Hidrográfica do rio Piracuruca (SBHRP), que situa-se entre os estados do Ceará e do Piauí e tem o rio Piracuruca como seu principal recurso hídrico. Essa Sub-bacia é periodicamente atingida por eventos pluviométricos extremos, secas e inundações, que associados aos fatores inerentes à vulnerabilidade social - contingente demográfico, nível de escolaridade, renda per capita, infraestrutura, qualidade do entorno das habitações, entre outros - convergem para potencializar as consequências dos desastres naturais.

Diante do que foi apresentado e considerando a relevância de estudos voltados ao conhecimento da realidade socioeconômica e, como tal, da vulnerabilidade socioespacial em bacias hidrográficas, a pesquisa teve como objetivo analisar a vulnerabilidade socioespacial da Subbacia Hidrográfica do rio Piracuruca à ocorrência de secas e inundações.

\section{LOCALIZAÇÃO E CARACTERIZAÇÃO DA ÁREA EM ESTUDO}

A Sub-bacia Hidrográfica do rio Piracuruca pertence à Bacia Hidrográfica do rio Longá
(BHRL) que, por sua vez, integra o conjunto dos principais afluentes da Bacia Hidrográfica do rio Parnaíba (BHRP) estando a mesma, com fluxo direcionado ao médio/baixo curso, conforme está representado no na Figura 1. A SBHRP situa-se na borda oriental da BHRP e setor nordeste da BHRL, entre os estados do Ceará e o do Piauí, em área considerada semiárida. A SBHRP drena uma área de $7.704 \mathrm{~km}^{2}$ e as principais nascentes do seu rio principal nascem na Serra da Ibiapaba, a altura do município de São Benedito, estado do Ceará, e desemboca no rio Longá a altura do município de São José do Divino, já no estado do Piauí. A referida Sub-bacia drena áreas de 20 municípios, desses 11 estão localizados em território piauiense e 9 no estado do Ceará.

A SBHRP exibe formações geológicas com domínio morfoestrutural e cronologia associada às Coberturas Detrito-Lateríticas/Cenozóicas e vulcanismo fissural/Mesozóico, além de falhas na porção oriental e preponderantemente no sentido NE-SE (CPRM, 2006a; 2006b; 2006c). A Subbacia está assentada sobre seis formações geológicas, quais sejam: Grupo Serra Grande (Período Siluriano); Formação Pimenteiras (Período Devoniano Inferior); Formação Cabeças (Período Devoniano Médio); Formação Sardinha (Período Cretáceo); Depósitos Colúvio-Eluviais (Período Neógeno) (CPRM, 2006a; 2006b; 2006c).

Sobre essas formações atuam processos erosivos de dissecação e de acumulação, onde se pode visualizar em direção ao estado do Piauí vertentes erodidas do Planalto da Ibiapaba, com formas que variam de forte a parcialmente dissecadas, devido atuação dos rios consequentes. Na sequência a Sub-bacia exibe relevo aplainado com formação de extensas áreas rebaixadas e periodicamente inundáveis (SANTOS, 2019).

As precipitações na SBHRP estão a sob influência Zona de Convergência Intertropical (ZCIT), Vórtices Ciclônicos de Altos Níveis (VCANs), Distúrbios Ondulatórios de Leste (DOL), Linhas de Instabilidade (LIs), Perturbações Ondulatórias nos Alísios (POA). Ressalta-se que a ZCIT é o principal sistema gerador de chuvas na área estudada, cuja movimentação está muito ligada aos fenômenos oceânicos El Niño Oscilação Sul (ENOS) e ao Dipolo do Atlântico, fato que vai gera anos com totais de precipitações normais ou com anomalias, negativas ou positivas (SANTOS, 2019).

De acordo com Koppen, a Sub-bacia do rio Piracuruca apresenta o clima BSh, caracterizado principalmente pela irregular distribuição de 
chuvas ao longo do ano, cuja evaporação e transpiração excedem os totais pluviométricos, classificando como clima seco semiárido.Ressalta-se que a área está sob influência do Planalto da Ibiapaba, devido ocorrência de chuvas orográficas. Desse modo, o quantitivo de precipitações varia de $860 \mathrm{~mm}$ a $1.710 \mathrm{~mm}$ anuais, temperaturas médias que oscilam de 20 a $27^{\circ} \mathrm{C}$, até 7 meses secos, evapotranspiração potencial que varia de 903 mm a 1643 mm, excedente hídrico de 100 a 1000 $\mathrm{mm}$ e déficits que variam de 30 a $730 \mathrm{~mm}$ anual (SANTOS, 2019).

O mosaico dos solos exibe ocorrência de 8 ordens e 11 subordens, a saber: os Neossolos (subordens: Neossolos Litólicos e Neossolos Quartzarênicos), recobertos por caatinga arbustiva e/ou carrasco; os Argissolos (subordem Amarela e Vermelha), recobertos por caatinga arbustiva; Os Latossolos (subordem Latossolo Amarelo), constituindo substrato para mapa plúvio-nebular; Os Planossolos (subordem Planossolo Háplico), que possibilita o desenvolvimento da mata plúvio-nebular; Os Plintossolos (subordens; Plintossolo Argilúvico e Plintossolo Pétrico), propiciando a ocorrência de carnaubal e caatinga arbustiva aberta; os Vertissolos (subordem Vertissolo Ebânico), com caatinga arbustiva; os Gleissolos (subordem Melânico), são recobertos por mata plúvionebular; os Chernossolos (subordem Argilúvico), possibilitando o crescimento de vegetação do tipo caatinga arbustiva (INDE, 2014; SANTOS, 2019).

Figura 1. Situação geográfica da Sub-bacia Hidrográfica do rio Piracuruca.

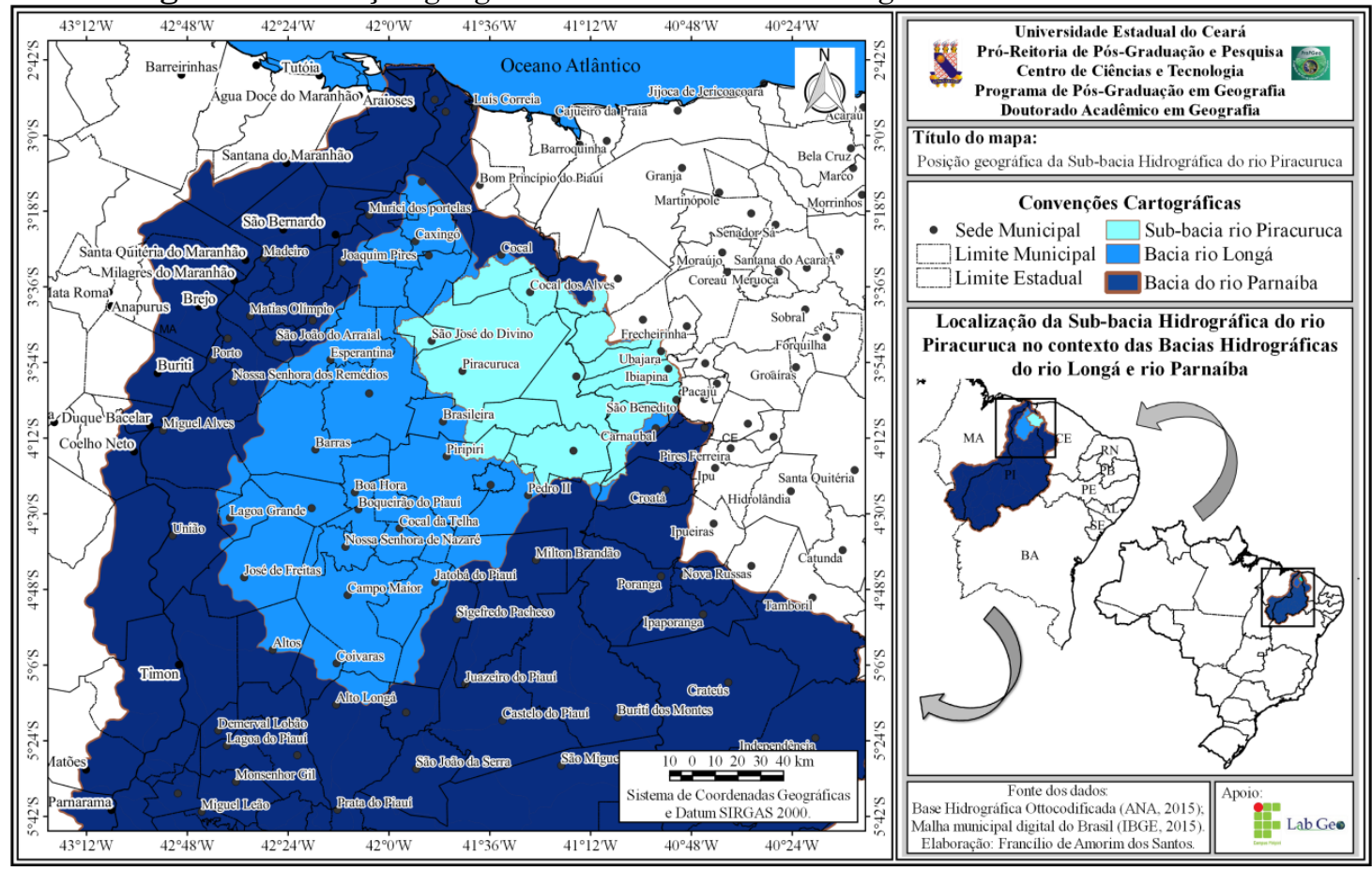

Fonte: Elaborado pelos autores (2019)

\section{PROCEDIMENTOS METODOLÓGICOS}

Os procedimentos descritos a seguir foram essenciais para a espacialização dos dados das variáveis elencadas para construção do índice de vulnerabilidade socioespacial (IVSE), a partir da adaptação da metodologia de Cunha et al. (2011) e (MENDES et al., 2011), que utiliza os conceitos de Criticidade (C), como o conjunto de características e comportamentos individuais que podem romper o sistema, e Capacidade de Suporte (CS), como o conjunto de infraestruturas territoriais que permitem à comunidade reagir em casos de desastre, para cada setor censitário da SBHRP.

Para elaboração do IVSE foi utilizado o software SPSS Statistics, versão 17, modelo de estatística multivariada Análise Fatorial (AF) e método de estimação Análise das Componentes Principais (ACP), a partir de variáveis demográficas, de infraestrutura, de saneamento básico, ambiental, econômica e social da população, por setor censitário, do censo demográfico de 2010. A AF/ACP representa um modelo/método para redução da quantidade de dados, quando se trabalha com grande número de variáveis - nesse estudo foram, inicialmente, 
consideradas 18 variáveis para Criticidade e 44 para Capacidade de Suporte (Quadro 1) - a um tamanho manejável em quanto se extrai o máximo de informações possíveis (FIELD, 2009; ROGERSON, 2012).

Quadro 1. Conjunto de variáveis utilizadas para a análise da Criticidade (C) e Capacidade de Suporte (CS) dea Sub-bacia Hidrográfica do rio Piracuruca.

\begin{tabular}{|c|c|}
\hline \multicolumn{2}{|r|}{ Criticidade (C) } \\
\hline Código & Variável \\
\hline $\mathrm{C} 01$ & Densidade de domicílios particulares permanentes \\
\hline $\mathrm{C} 02$ & Densidade populacional \\
\hline $\mathrm{C} 03$ & Pessoas com 0 a 5 anos de idade \\
\hline $\mathrm{C} 04$ & Pessoas residentes - 65 ou mais de idade \\
\hline $\mathrm{C} 05$ & Pessoas responsáveis, do sexo feminino. \\
\hline $\mathrm{C} 06$ & Pessoas alfabetizadas com 5 ou mais anos de idade \\
\hline $\mathrm{C} 07$ & Pessoas responsáveis alfabetizadas \\
\hline $\mathrm{C08}$ & Pessoas responsáveis, do sexo masculino. \\
\hline $\mathrm{C} 09$ & Pessoas responsáveis alfabetizadas, do sexo masculino. \\
\hline $\mathrm{C} 10$ & Homens responsáveis pelo domicílio particular \\
\hline $\mathrm{C} 11$ & Mulheres responsáveis pelo domicílio particular \\
\hline $\mathrm{C} 12$ & Pessoas residentes \\
\hline $\mathrm{C} 13$ & Total do rendimento nominal mensal dos domicílios particulares permanentes \\
\hline $\mathrm{C} 14$ & Total do rendimento nominal mensal dos domicílios particulares improvisados \\
\hline $\mathrm{C} 15$ & Pessoas responsáveis com rendimento nominal mensal de mais de $1 / 2$ a 1 salário mínimo \\
\hline $\mathrm{C} 16$ & Pessoas responsáveis com rendimento nominal mensal de mais de 1 a 2 salários mínimos \\
\hline $\mathrm{C} 17$ & Pessoas responsáveis com rendimento nominal mensal de mais de 5 a 10 salários mínimos \\
\hline C18 & Pessoas responsáveis sem rendimento nominal mensal \\
\hline \multicolumn{2}{|r|}{ Capacidade de Suporte (CS) } \\
\hline Código & Variável \\
\hline CS01 & $\begin{array}{l}\text { Domicílio particular permanentes com banheiro de uso exclusivo dos moradores ou sanitário } \\
\text { e esgotamento sanitário via rio, lago ou mar }\end{array}$ \\
\hline CS02 & Domicílios particulares permanentes com lixo coletado \\
\hline CS03 & Domicílios particulares permanentes com lixo queimado na propriedade \\
\hline CS04 & Domicílios particulares permanentes com lixo jogado em rio, lago ou mar \\
\hline CS05 & Domicílios particulares permanentes com energia elétrica \\
\hline CS06 & Domicílios particulares permanentes sem energia elétrica \\
\hline CS07 & Domicílios particulares permanentes com 1 morador \\
\hline CS08 & Domicílios particulares permanentes com 2 a 4 moradores \\
\hline CS09 & Domicílios particulares permanentes com 5 a 9 moradores \\
\hline CS10 & Domicílios particulares permanentes com 10 ou mais moradores \\
\hline CS11 & Domicílios particulares permanentes próprios - Existe iluminação pública \\
\hline CS12 & Domicílios particulares permanentes alugados - Existe iluminação pública \\
\hline CS13 & Domicílios particulares permanentes cedidos - Existe iluminação pública \\
\hline CS14 & Domicílios particulares permanentes próprios - Existe pavimentação \\
\hline CS15 & Domicílios particulares permanentes alugados - Existe pavimentação \\
\hline CS16 & Domicílios particulares permanentes cedidos - Existe pavimentação \\
\hline CS17 & Domicílios particulares permanentes próprios - Existe bueiro/boca-de-lobo \\
\hline CS18 & Domicílios particulares permanentes alugados - Existe bueiro/boca-de-lobo \\
\hline CS19 & Domicílios particulares permanentes cedidos - Existe bueiro/boca-de-lobo \\
\hline $\mathrm{CS} 20$ & Domicílios particulares permanentes próprios - Existe rampa para cadeirantes \\
\hline CS21 & Domicílios particulares permanentes alugados - Existe rampa para cadeirantes \\
\hline CS22 & Domicílios particulares permanentes cedidos - Existe rampa para cadeirantes \\
\hline CS23 & Domicílios particulares permanentes próprios - Existe arborização \\
\hline CS24 & Domicílios particulares permanentes alugados - Existe arborização \\
\hline CS25 & Domicílios particulares permanentes cedidos - Existe arborização \\
\hline CS26 & Domicílios particulares permanentes próprios - Existe esgoto a céu aberto \\
\hline CS27 & Domicílios particulares permanentes alugados - Existe esgoto a céu aberto \\
\hline CS28 & Domicílios particulares permanentes cedidos - Existe esgoto a céu aberto \\
\hline CS29 & Domicílios particulares permanentes próprios - Existe lixo acumulado nos logradouros \\
\hline CS30 & Domicílios particulares permanentes alugados - Existe lixo acumulado nos logradouros \\
\hline
\end{tabular}

Fonte: Santos (2019). 
Dessa forma, para produção dos resultados ligados ao IVSE aquiriram-se os seguintes arquivos: vetorial, ligado aos setores censitários utilizados para realização do Censo de 2010, pelo Instituto Brasileiro de Geografia e Estatística (IBGE); e alfanumérico, que diz respeito às planilhas de dados - demográficas, de infraestrutura, saneamento básico, ambiental, econômica e social da população - por setores censitários, obtidos a partir dos microdados do universo do Censo Demográfico 2010 (IBGE, 2018). Ressalta-se que os limites da Sub-bacia do rio Piracuruca abrangem 296 (duzentos e noventa e seis) setores censitários, sendo 186 setores rurais e 110 urbanos.

Diga-se, ainda, que para a identificação das principais componentes de $\mathrm{C}$ e de CS e, como tal, avaliação do IVSE da SBHRP empregou-se, também, o método de rotação ortogonal Varimax com normalização Kaiser, para integração dos dados censitários do IBGE para o ano de 2010. Esse método busca agregar um menor número de variáveis no que diz respeito a cada fator (FIELD, 2009). Ressalta-se que para validação da AF/ACP foram aplicados dois testes, quais sejam: Kaiser-Meyer-Olkin (KMO), que varia entre 0 e 1 , sendo que igual ou acima de 0,7 é considerado mediano (MALHOTRA, 2001, apud BAKKE; LEITE; SILVA, 2008); e o teste de esfericidade de Bartlett, que testa a hipótese nula de que a matriz de correlações original (R) é uma matriz identidade, considerando-se que a matriz $\mathrm{R}$ tenha todos os coeficientes de correlação iguais a 0 , devendo apresentar valor de significância < 0,05 (FIELD, 2009).

Destaca-se que a redução do número de variáveis ocorreu por meio da identificação de suas comunalidades e das suas correlações. Pois as variáveis semelhantes entre si, o nível de semelhança e o grau de explicação que os fatores fornecem ao modelo criado, tendo como produto os scores (MARTINEZ; FERREIRA, 2010). Reitera-se que se considerou a AF/ACP como modelo/método para redução do número de variáveis redundantes e possibilitar o agrupamento das remanescentes em fatores, considerando-se a efetuação de 8 (oito) etapas, conforme sugere a proposta de Cunha et al. (2011), conforme está representado na Figura 2.

Figura 2. Roteiro metodológico para Análise Fatorial (AF)/Análise de Componentes Principais (ACP).

\begin{tabular}{|c|c|}
\hline \multirow{6}{*}{$\tilde{\omega}_{\tilde{N}}^{\infty}$} & Normalização das variáveis \\
\hline & Execução da AF \\
\hline & Avaliação da matriz de correlação dos dados \\
\hline & $\begin{array}{l}\text { Exclusão dos dados redundantes (KMO >0,5 e esfericidade } \\
\text { de Bartlett }<0,05)\end{array}$ \\
\hline & $\begin{array}{l}\text { Interpretação e escalamento dos fatores / modo como } \\
\text { influenciam a vulnerabilidade social ( } x-1 \text { os scores fatoriais } \\
\text { positivos que contribuem para diminuir a vulnerabilidade) }\end{array}$ \\
\hline & Combinação dos scores fatoriais num único valor \\
\hline \multirow{2}{*}{$\frac{\omega}{0}$} & Exportação dos dados do SPSS para o QGIS \\
\hline & Classificação dos resultados finais (CUTTER et al., 2003) \\
\hline
\end{tabular}

Fonte: Cunha et al. (2011).

Ressalta-se que para obtenção dos resultados para a C e a CS utilizou-se da soma ponderada, a partir de adaptações à proposta metodológica de Cunha et al. (2011), que trabalhou com Análise Fatorial ligada à Criticidade e Capacidade de Suporte, para conhecimento da Vulnerabilidade.
Ao passo que para a obtenção do valor de $\mathrm{C}$ e de CS para cada setor censitário considerou-se a soma do produto da comunalidade de cada variável por seu valor padronizado.

Desse modo, para análise da Criticidade (C), inicialmente, trabalhou-se com um grupo de 18 
variáveis que, posteriormente à execução da análise fatorial teve apenas uma variável excluída. Pois quando executada a primeira rodada para obtenção dos fatores uma das variáveis apresentou coeficiente de comunalidade abaixo de 0,5, logo não estava sendo bem representada na modelagem e foi desconsiderada. Realizado esse procedimento pode-se calcular a Criticidade para os setores censitários da SBHRP com base no fator principal e emprego da Equação 1:
Onde: $\mathrm{C}=$ Criticidade; $\mathrm{Fn}=$ Fatores de Criticidade resultantes da AF/ACP; n $=1$ a 4 .

Os valores de C para cada setor censitário, considerando a Equação 1, foram exportados do formato excel (*.csv), para a plataforma de trabalho no QGIS, onde se procedeu à classificação desses dados por meio do método quebra naturais (jenks) no referido SIG, resultando em 5 classes de C, conforme é apresentado na Tabela 1 .

$C=\left(-F_{1}\right)+\left(-F_{2}\right)+F_{3}+F_{4}$

Tabela 1. Intervalos, classes atribuídas e notas de Criticidade (C) para os 296 setores censitários da Sub-bacia Hidrográfica do rio Piracuruca, para o ano de 2010.

\begin{tabular}{ccc}
\hline Intervalos de C & Classes atribuídas & Notas \\
\hline$-28,05840740$ a $-11,93914040$ & Muito baixa & 1 \\
$-11,93914040$ a $-4,44841431$ & Baixa & 2 \\
$-4,44841431$ a 0,69792666 & Média & 3 \\
0,69792666 a 4,84258660 & Alta & 5 \\
4,84258660 a 11,44525901 & Muito alta & 5 \\
\hline
\end{tabular}

Fonte: Elaborada pelos autores (2019).

Por seu turno, para conhecimento da Capacidade de Suporte (CS) foram considerados um grupo de 44 (quarenta e quatro) variáveis, que após execução de 4 testes da análise fatorial resultou na exclusão de 14 (quatorze) variáveis, posto que apresentassem comunialidade superior a 0,5. Em seguida pode-se aplicar a Equação 2 para obtenção da CS para os setores censitários da Sub-bacia estudada, considerando-se o fator principal e sua influência positiva ou negativa nos resultados alcançados.

$C S=\left(-F_{1}\right)+\left(-F_{2}\right)+\left(-F_{3}\right)+F_{4}+F_{5}+\left(-F_{6}\right)+F_{7}$
Onde: $\mathrm{CS}=$ Capacidade de Suporte Fn = Fatores de Capacidade de Suporte resultantes da $\mathrm{AF} / \mathrm{ACP} ; \mathrm{n}=1$ a 7 .

Os valores resultantes da aplicação da Equação 2 possibilitaram a identificação da CS por setor censitário da SBHRP. Os referidos valores foram exportados do formato excel (*.csv) para manuseio no QGIS. Nesse SIG efetuou-se a classificação dos dados, mencionados, por meio da opção graduado e método quebra naturais (jenks), onde se geraram 5 classes de CS, que estão apresentadas na Tabela 2 .

Tabela 2. Intervalos, classes atribuídas e notas de Capacidade de Suporte (CS) para os 296 setores censitários da Sub-bacia Hidrográfica do rio Piracuruca, para o ano de 2010.

\begin{tabular}{ccc}
\hline Intervalos de C & Classes atribuídas & Notas \\
\hline$-66,42206630$ a $-29,59488850$ & Muito baixa & 5 \\
$-29,59488850$ a $-12,85094580$ & Baixa & 4 \\
$-12,85094580$ a $-1,80323566$ & Média & 3 \\
$-1,80323566$ a 5,66628248 & Alta & 2 \\
5,66628248 a 17,74679925 & Muito alta & 1
\end{tabular}

Fonte: Elaborada pelos autores (2019).

Finalizados as etapas para obtenção dos valores de Criticidade e de Capacidade de Suporte, pode ser executado o cálculo para obtenção do índice de vulnerabilidade socioespacial (IVSE) por setor censitário, considerando-se o ano de 2010, conforme e está expresso na Equação 3:

\section{IVSE $=\mathrm{CxCS}$}

Onde: IVSE = índice de vulnerabilidade socioespacial; $\mathrm{C}=$ Criticidade CS = Capacidade de Suporte.

A espacialização das classes definidas, anteriormente, para a Criticidade e para a 
Capacidade de Suporte subsidiou a delimitação das classes para o IVSE da Sub-bacia do rio
Piracuruca, conforme pode-se observar no Quadro 1.

Quadro 1. Intervalos, classes atribuídas e notas do Índice de vulnerabilidade sócio-espacial (IVSE) da Sub-bacia Hidrográfica do rio Piracuruca.

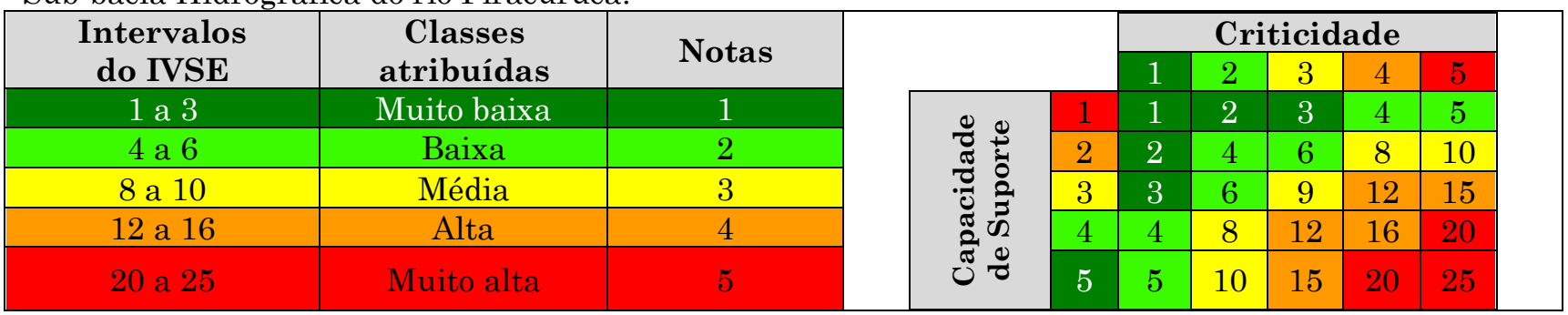

Fonte: Adaptado de Mendes et al. (2011).

\section{RESULTADOS E DISCUSSÃO}

A seguir será realizada análise do resultado oriundo da AF/ACP, que considerou a Criticidade - ligada ao perfil demográfico, gênero, renda e nível de instrução da população - e a Capacidade de Suporte, que diz respeito à infraestrutura disponibilizada à população permitindo-a reagir a eventos considerados desastres naturais.

Como forma de simplificar a interpretação dos Fatores produzidos para Criticidade, realizou-se a rotação ortogonal por meio do método Varimax, onde cada variável foi associada ao fator que melhor se correlacionou após a rotação Varimax com a normalização Kaiser, cujos valores das cargas fatoriais foram maiores que 0,50 para todas as variáveis. Ressalta-se que o modelo para Criticidade foi validado pelos testes KMO e esfericidade de Bartlett que, respectivamente, apresentaram valor de 0,813 e significância (Sig.) igual a 0,00, considerado adequado.

Desse modo, os 4 (quatro) Fatores resultantes respondem por $86,209 \%$ da variância acumulada no que diz respeito às variáveis elencadas para análise da Criticidade, sendo que a variância acumulada rotacionada foi a seguinte: no Fator 1 foi de 55,215\%; no Fator 2 de $69,866 \%$; no terceiro foi $79,168 \%$; no quarto de $86,209 \%$. Dessa forma, assevera-se que o Fator 1 consegue explicar $55,215 \%$ da variância dos dados originais, ao passo que os outros três fatores juntos explicam 30,995\%.

O Quadro 2 apresenta a análise fatorial exploratória, com as variáveis dominantes nos Fatores de Criticidade que mais influenciaram a análise. Observa-se que: o Fator 1 apresentou correlação alta e positiva e promove a redução da vulnerabilidade socioespacial; o segundo Fator exibiu correlação alta e positiva e possibilita a redução da vulnerabilidade; no Fator 3 observase correlação alta e positiva e contribui para acentur a vulnerabilidade; o Fator 4 possui correlação positiva e muito alta, contribuindo para aumentar a vulnerabilidade na Sub-bacia estudada.

A integração e a espacialização dos fatores de maior influência para construção da Criticidade referente aos 296 setores censitários da SBHRP permitiu a elaboração da Figura 2. Nesse observa-se o predomínio da classe alta, que ocorre em $87(29,4 \%)$ setores da Sub-bacia em questão. Segue-se a classe média que se distribui por $83(28,0 \%)$ setores. Por seu turno, as classes muito alta, baixa e muito baixa situam-se em 67 $(22,6 \%), 43(14,5 \%)$ e $16(5,4 \%)$ setores da Subbacia pesquisada, respectivamente. 
Quadro 2. Síntese das variáveis de maior correlação do fator Criticidade (C) para a Sub-bacia Hidrográfica do rio Piracuruca, para o ano 2010.

\begin{tabular}{|c|c|}
\hline Fator (Sinal) & Variáveis de maior influência \\
\hline \multirow{8}{*}{$\begin{array}{c}1(-) \\
\text { Pessoas } \\
\text { responsáveis } \\
\text { Alfabetizadas, } \\
\text { Gênero, } \\
\text { Residente, Renda } \\
\text { e Estrutura } \\
\text { Etária }\end{array}$} & C08 - Pessoas responsáveis, do sexo masculino $(+0,949)$ \\
\hline & $\begin{array}{l}\text { C15 - Pessoas responsáveis com rendimento nominal mensal de mais } \\
\text { de } 1 / 2 \text { a } 1 \text { salário mínimo }(+0,891)\end{array}$ \\
\hline & C12 - Pessoas residentes $(+0,885)$ \\
\hline & C06 - Pessoas alfabetizadas com 5 ou mais anos de idade $(+0,878)$ \\
\hline & C09 - Pessoas responsáveis alfabetizadas, do sexo masculino $(+0,870)$ \\
\hline & C11 - Mulheres responsáveis pelo domicílio particular $(+0,866)$ \\
\hline & C07 - Pessoas responsáveis alfabetizadas $(+0,751)$ \\
\hline & C03 - Pessoas com 0 a 5 anos de idade $(+0,683)$ \\
\hline \multirow{3}{*}{$\begin{array}{c}2(-) \\
\text { Renda Nominal } \\
\text { do Domicilio }\end{array}$} & $\begin{array}{l}\text { C17 - Pessoas responsáveis com rendimento nominal mensal de mais } \\
\text { de } 5 \text { a } 10 \text { salários mínimos }(+0,911)\end{array}$ \\
\hline & $\begin{array}{l}\text { C13 - Total do rendimento nominal mensal dos domicílios } \\
\text { particulares permanentes }(+0,813)\end{array}$ \\
\hline & $\begin{array}{l}\text { C16 - Pessoas responsáveis com rendimento nominal mensal de mais } \\
\text { de } 1 \text { a } 2 \text { salários mínimos }(+0,686)\end{array}$ \\
\hline \multirow{4}{*}{$\begin{array}{c}3(+) \\
\text { Pessoas } \\
\text { responsáveis por } \\
\text { Gênero e } \\
\text { Estrutura Etária }\end{array}$} & C04 - Pessoas residentes com 65 ou mais de idade $(+0,785)$ \\
\hline & C10 - Homens responsáveis pelo domicílio particular $(+0,774)$ \\
\hline & $\begin{array}{lllll}\begin{array}{l}\text { C18 - Pessoas responsáveis sem rendimento nominal mensal } \\
(+0,704)\end{array} & & & \\
\end{array}$ \\
\hline & C05 - Pessoas responsáveis, do sexo feminino $(+0,692)$ \\
\hline \multirow{2}{*}{$\begin{array}{c}4(+) \\
\text { Densidade } \\
\text { Populacional e } \\
\text { Domicílios } \\
\text { Particulares } \\
\end{array}$} & C02 - Densidade populacional $(+0,982)$ \\
\hline & C01 - Densidade de domicílios particulares permanentes $(+0,980)$ \\
\hline
\end{tabular}

Fonte: Elaborado pelos autores (2019).

Figura 2. Criticidade (C) dos setores censitários da Sub-bacia Hidrográfica do rio Piracuruca, para o

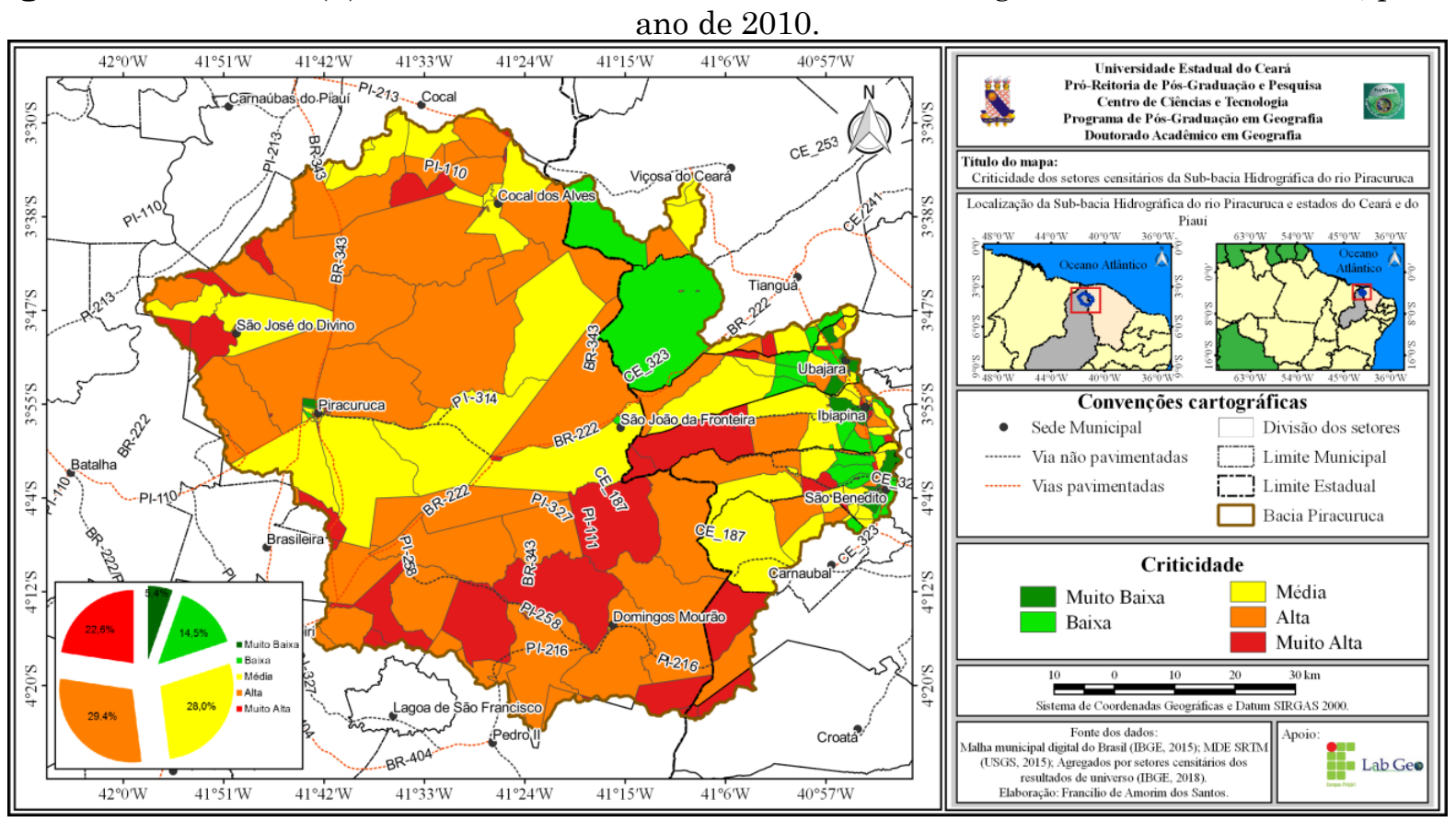

Fonte: Elaborado pelos autores (2019). 
Frente o exposto, pode-se afirmar as classes alta e muito alta na Sub-bacia estudada dispersam-se, principalmente, pelos setores censitários rurais dos municípios piauienses. Posto que apresentem maior aporte de pessoas com faixa etária extrema, ou seja, 0 a 5 anos e com 65 anos ou mais e demandam mais atenção e cuidado em relação à manifestação de eventos pluviométricos extremos, devido dificuldades para locomoção. Ressalta-se, ainda, que a presença de mulheres responsáveis pela renda do domicílio e a ocorrência de pessoas responsáveis sem rendimento ou com renda até 1 salário mínimo contrbiui para aumentar a vulnerabilidade socioespacial.

Nesse sentido, Fragoso, Gehlen e Silva (2012) destacam que embora haja uma divisão desigual dos recursos entre os vários grupos econômicos na sociedade, é a mulher em grande parte, bem como os demais que não possuem poder reivindicativo, a exclusão de quaisquer benefícios diretos que isso possa trazer. Fato que justifica dizer que a mulher se torna mais vulnerável que homem, não pelas suas características comportamentais, mas pela exclusão social que sofre.

Ao examinar-se o Quadro 3, que se relaciona à Capacidade de Suporte, observa-se que: o Fator 1 exibe correlação alta e forte e contribui para redução da vulnerabilidade; o Fator 2 possui alta correlação e sua contribuição reduz a vulnerabilidade; o terceiro Fator apresenta alta correlação e possibilita a redução da ocorrência de inundações; o Fator 4 demonstra alta correlação e diminui as condições de suporte aos desastres naturais na Sub-bacia; o Fator 5 possui alta correlação e influência negativamente a CS; no sexto Fator percebe-se correlação forte e contribuição para o aumento da Capacidade de Suporte da população da SBHRP; enquanto no Fator 7 observa-se contribuição relevante para reduzir a Capacidade de Suporte da população da SBHRP a eventos naturais, posto que um maior contigente populacional residindo em uma mesma residência demanda maior aporte de serviços, a exemplo da necessidade de medicamentos, gêneros alimentícios, roupas, etc.

Esses dados permitiram a integração dos Fatores e espacialização da Capacidade de Suporte dos 296 setores censitários da SBHRP (Figura 3). Nesse observa-se o predomínio da classe muito alta, distribuída por 137 (46,3\%) setores da Sub-bacia. Por sua vez, a classe alta foi a segunda mais representativa, sendo identificada em 69 (23,3\%) setores. Por seu turno, as classes média, baixa e muito baixa tiveram ocorrência em 44 (14,9\%), 36 (12,2\%), 10 $(3,4 \%)$ dos setores da Sub-bacia.

Ressalta-se que embora a SBHRP apresente preponderantemente alta a muito alta capacidade para suportar secas e inundações periódicas, detaca-se que seus setores exibem Capacidade de Suporte distinta e demandam melhorias na qualidade ambiental a partir da elaboração de adequado planejamento, considerando a melhoria dos indicadores ambientais como condição fundamental para redução da vulnerabilidade. 
Quadro 3. Síntese das variáveis de maior correlação do fator Capacidade de Suporte (CS), para a Subbacia Hidrográfica do rio Piracuruca ano 2010.

\begin{tabular}{|c|c|}
\hline Fator (Sinal) & Variáveis de maior influência \\
\hline \multirow{13}{*}{$\begin{array}{c}1(\text { ) } \\
\text { Infraestrutura domiciliar } \\
\text { (abastecimento de água da } \\
\text { rede geral, coleta do lixo, } \\
\text { iluminação, pavimentação e } \\
\text { arborização) }\end{array}$} & $\begin{array}{l}\text { CS26 - Domicílios particulares permanentes cedidos com iluminação pública } \\
(+0,884)\end{array}$ \\
\hline & $\begin{array}{l}\text { CS27 - Domicílios particulares permanentes próprios com pavimentação } \\
(+0,879)\end{array}$ \\
\hline & $\begin{array}{l}\begin{array}{l}\text { CS29 - Domicílios particulares permanentes cedidos com pavimentação } \\
(+0,873)\end{array} \\
\end{array}$ \\
\hline & CS38 - Domicílios particulares permanentes cedidos com arborização $(+0,873)$ \\
\hline & CS36 - Domicílios particulares permanentes próprios com arborização $(+0,865)$ \\
\hline & $\begin{array}{l}\text { CS24 - Domicílios particulares permanentes próprios com iluminação pública } \\
(+0,853)\end{array}$ \\
\hline & $\begin{array}{l}\text { CS25 - Domicílios particulares permanentes alugados com iluminação pública } \\
(+0,841)\end{array}$ \\
\hline & CS15 - Domicílios particulares permanentes com lixo coletado $(+0,836)$ \\
\hline & V04 - Domicílios particulares permanentes alugados $(+0,831)$ \\
\hline & CS37 - Domicílios particulares permanentes alugados com arborização $(+0,824)$ \\
\hline & $\begin{array}{l}\text { CS28 - Domicílios particulares permanentes alugados com pavimentação } \\
(+0,817)\end{array}$ \\
\hline & $\begin{array}{l}\text { CS07 - Domicílios particulares permanentes com abastecimento de água da } \\
\text { rede geral }(+0,698)\end{array}$ \\
\hline & $\begin{array}{l}\text { CS16 - Domicílios particulares permanentes com lixo queimado na propriedade } \\
(-0,612)\end{array}$ \\
\hline \multirow{5}{*}{$\begin{array}{c}2(-) \\
\text { Tipo e quantidade de } \\
\text { moradores por domicílio e } \\
\text { infraestrutura (presença de } \\
\text { energia elétrica e tipo de } \\
\text { banheiro) }\end{array}$} & CS01 - Domicílios particulares permanentes do tipo casa $(+0,938)$ \\
\hline & CS18 - Domicílios particulares permanentes com energia elétrica $(+0,913)$ \\
\hline & CS21 - Domicílios particulares permanentes com 2 a 4 moradores $(+0,875)$ \\
\hline & $\begin{array}{l}\text { CS13 - Domicílios particulares permanentes com banheiro de uso exclusivo dos } \\
\text { moradores ou sanitário e esgotamento sanitário via fossa rudimentar }(+0,835)\end{array}$ \\
\hline & CS20 - Domicílios particulares permanentes com 1 morador $(+0,728)$ \\
\hline \multirow{3}{*}{$\begin{array}{c}3(-) \\
\text { Infraestrutura domiciliar (tipo } \\
\text { de bueiro) }\end{array}$} & $\begin{array}{l}\text { CS32 - Domicílios particulares permane } \\
(+0,917)\end{array}$ \\
\hline & $\begin{array}{l}\text { CS30 - Domicílios particulares permanentes próprios com bueiro/boca-de-lobo } \\
(+0,909)\end{array}$ \\
\hline & $\begin{array}{l}\text { CS31 - Domicílios particulares permanentes alugados com bueiro/boca-de-lobo } \\
(+0,856)\end{array}$ \\
\hline \multirow{3}{*}{$\begin{array}{c}4(+) \\
\text { Infraestrutura domiciliar (tipo } \\
\text { de esgoto) }\end{array}$} & $\begin{array}{l}\text { CS39 - Domicílios particulares permanentes próprios com esgoto a céu aberto } \\
(+0,837)\end{array}$ \\
\hline & $\begin{array}{l}\text { CS41 - Domicílios particulares permanentes cedidos com esgoto a céu aberto } \\
(+0,789)\end{array}$ \\
\hline & $\begin{array}{l}\text { CS40 - Domicílios particulares permanentes alugados com esgoto a céu aberto } \\
(+0,760)\end{array}$ \\
\hline \multirow{3}{*}{$\begin{array}{l}5(+) \\
\text { Infraestrutura domiciliar } \\
\text { (acumulo de lixo nos } \\
\text { logradouros) }\end{array}$} & $\begin{array}{l}\text { CS43 - Domicílios particulares permanentes alugados com lixo acumulado nos } \\
\text { logradouros }(+0,880)\end{array}$ \\
\hline & $\begin{array}{l}\text { CS44 - Domicílios particulares permanentes cedidos com lixo acumulado nos } \\
\text { logradouros }(+0,868)\end{array}$ \\
\hline & $\begin{array}{l}\text { CS42 - Domicílios particulares permanentes próprios com lixo acumulado nos } \\
\text { logradouros }(+0,857)\end{array}$ \\
\hline \multirow{3}{*}{$\begin{array}{c}6(-) \\
\text { Infraestrutura (acessibilidade) }\end{array}$} & $\begin{array}{l}\text { CS33 - Domicílios particulares permanentes próprios com rampa para } \\
\text { cadeirantes }(+0,880)\end{array}$ \\
\hline & $\begin{array}{l}\text { CS35 - Domicílios particulares permanentes cedidos com rampa para } \\
\text { cadeirantes }(+0,866)\end{array}$ \\
\hline & $\begin{array}{l}\text { CS34 - Domicílios particulares permanentes alugados com rampa para } \\
\text { cadeirantes }(+0,705)\end{array}$ \\
\hline $\begin{array}{c}7(+) \\
\text { Quantidade de moradores } \\
\text { domicílio } \\
\end{array}$ & CS22 - Domicílios particulares permanentes com 5 a 9 moradores $(+0,632)$ \\
\hline
\end{tabular}

Fonte: Elaborado pelos autores (2019). 
Figura 3. Capacidade de Suporte (CS) dos setores censitários da Sub-bacia Hidrográfica do rio Piracuruca, para o ano de 2010.

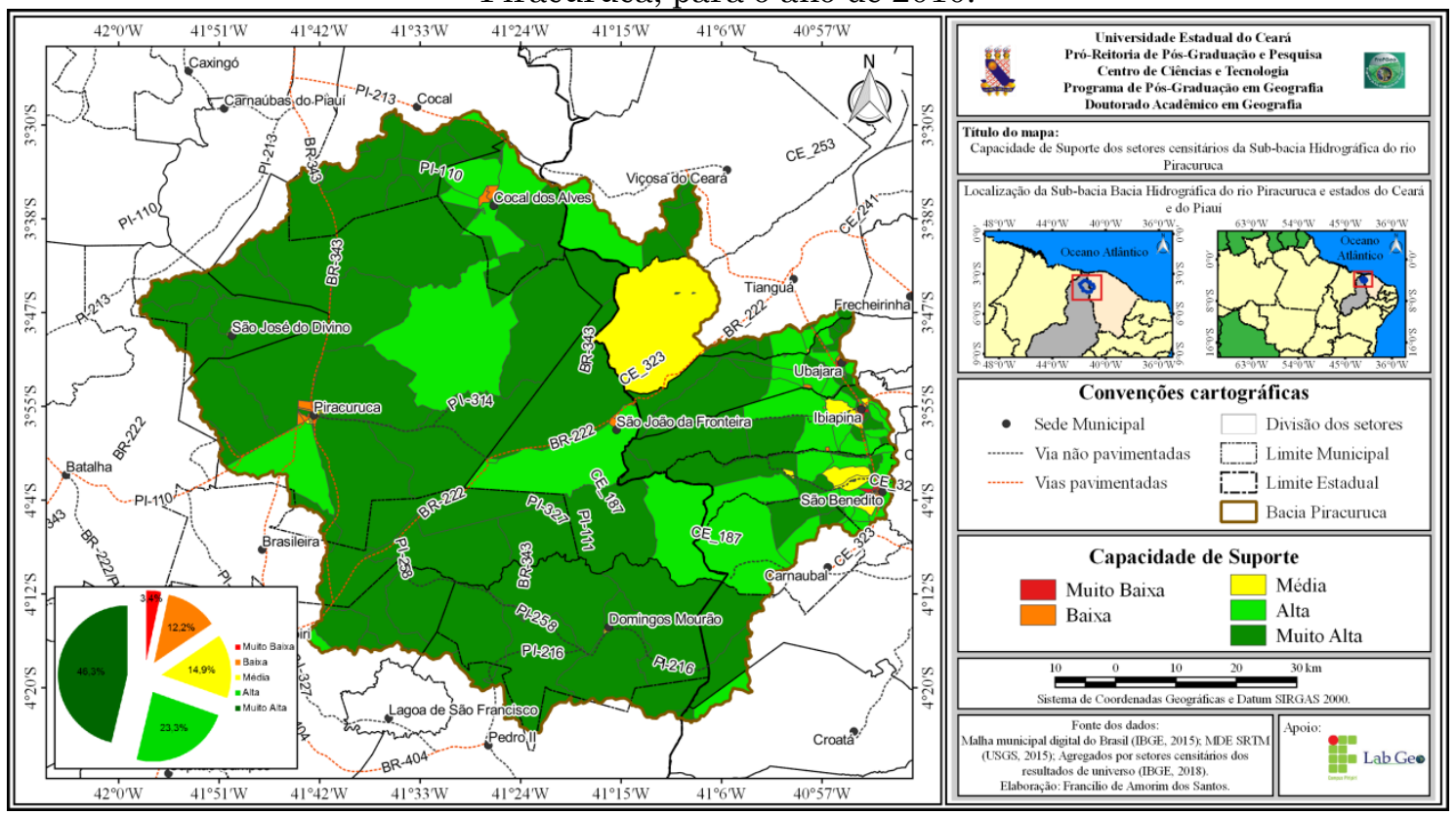

Fonte: Elaborado pelos autores (2019).

Quando integradas as variáveis ligadas a Criticidade e a Capacidade de Suporte foi possível construir o índice de vulnerabilidade socioespacial (IVSE). Nesse nota-se a preponderância da classe de vulnerabilidade baixa (Figura 4), cuja distribuição deu-se por 172 $(58,1 \%)$ setores da Sub-bacia pesquisada. A essa classe segue-se a vulnerabilidade média, que ocorre em $56(18,9 \%)$ setores da SBHRP. As demais classes têm ocorrência pontual, onde a classe alta foi identificada em $36(12,2 \%)$ setores, principalmente nos municípios de Cocal dos Alves, Piracuruca e São Benedito; enquanto a classe muito baixa ocorreu em 31 (10,5\%) setores; a classe muito alta apareceu em apenas $1(0,3 \%)$, que se localiza no município cearense de São Benedito.

Figura 4. Índice de vulnerabilidade socioespacial (IVSE) dos setores censitários da Sub-bacia Hidrográfica do rio Piracuruca, para o ano de 2010.

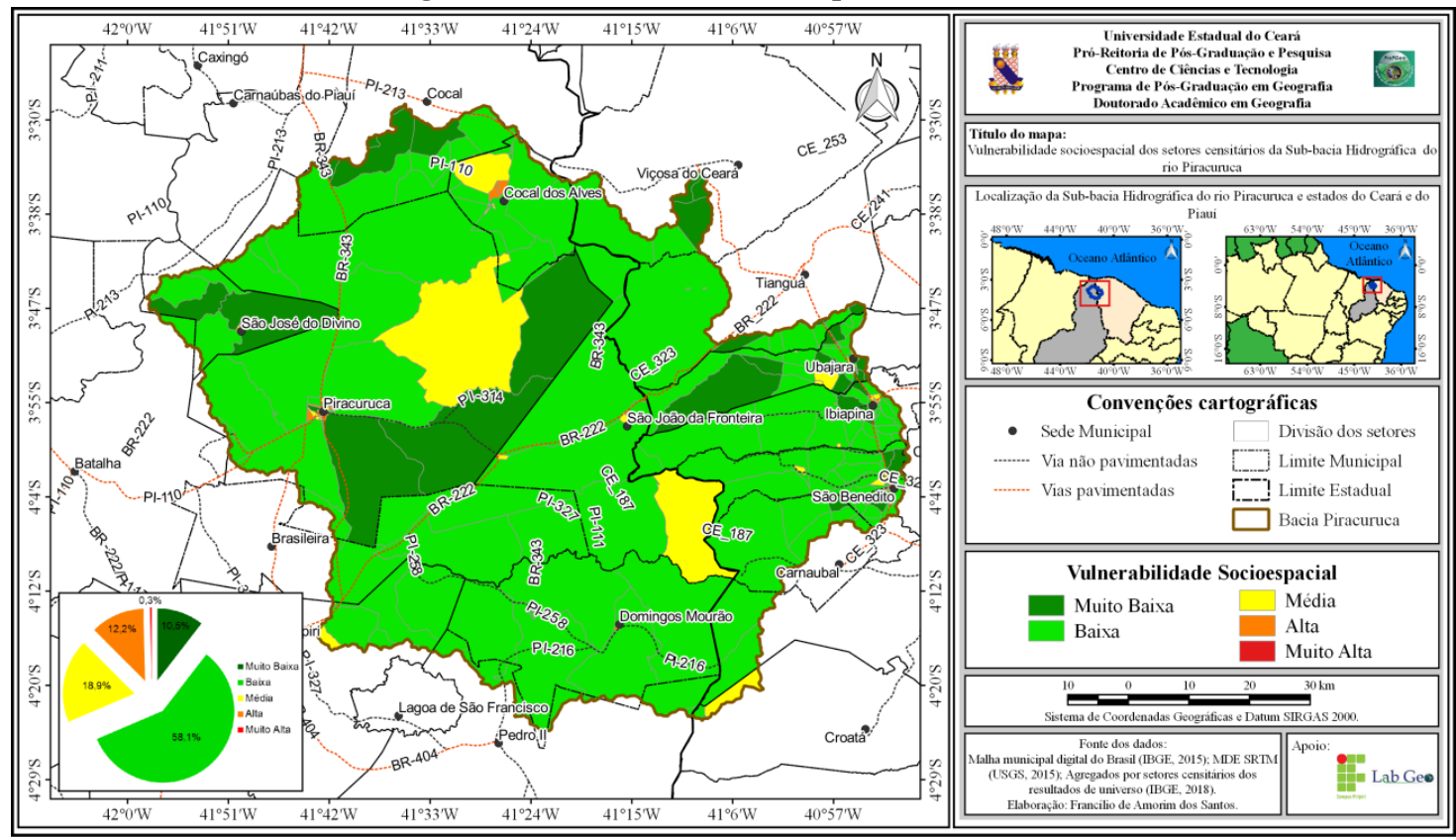

Fonte: Elaborados pelos autores (2019). 
Observa, desse modo, a diversidade dos setores da Sub-bacia, também, em relação ao IVSE demanda investimentos naqueles setores com maior Criticidade e menor Capacidade de Suporte, fato que irá reduzir a vulnerabilidade da população à ocorrência de desastres naturais, particularmente as secas e inundações.

\section{CONSIDERAÇÕES FINAIS}

A relevância da metodologia aplicada que se utilizou do modelo estatístico Análise Fatorial e método Análise de Componentes Principais como perspectiva para o agrupamento de variáveis demográficas, de infraestrutura, saneamento básico, ambiental, econômica e social da população. Ressalta-se que esse agrupamento resultou na construção de um índice, sumamente importante para o conhecimento da vulnerabilidade socioespacial da Sub-bacia Hidrográfica do rio Piracuruca.

Desse modo, o predomínio da classe alta de Criticidade, frequente em $87(29,4 \%)$ da Subbacia, sugere a necessidade de investimentos para melhoria da qualidade de vida, partircularmente da renda per capita, abertura de novos postos de emprego e estratégias para alfabetização dos residentes. Pois são essenciais ao aumento da capacidade da população para resistir a episódios de secas e inundações.

Ressalta-se, também, que o preponderância da classe muito alta de Capacidade de Suporte, que ocorre por $137(46,3 \%)$ setores, permite inferir que a Sub-bacia disponibiliza adequada infraestrutura à população para reagir as secas e as inundações. Contudo, esforços governamentais devem ser empreendidas no sentido de ampliar a qualidade ambiental, a partir de adequado planejamento e melhoria dos indicadores ambientais, como condição elementar dotar a população de instrumentos para regir a eventuais secas e inundações.

Como síntese da Criticidade e da Capacidade de Suporte o índice de vulnerabilidade socioespacial apontou prevalência da classe média, que se distribui por $56(18,9 \%)$ setores da Sub-bacia. Fato esse que demanda atenção, devendo-se tomar como ponto de partida a melhoria nos indicadores quantitativos referentes à população mais mais vulnerável, como forma de reduzir a Criticidade e aumentar a Capacidade de Suporte as secas e as inundações na área pesquisada.

\section{REFERÊNCIAS}

BAKKE, H. A.; LEITE, A. S. M.; SILVA, L. B. Estatística multivariada: aplicação da análise fatorial na engenharia de produção. Revista Gestão Industrial, v.04, n.04, p.01-14, 2008. https://doi.org/10.3895/S180804482008000400001

BRASIL. Ministério da Integração Nacional. Secretaria Nacional de Defesa Civil. Centro de Nacional de Gerenciamento de Riscos e Desastres. Anuário brasileiro de desastres naturais: 2013. - Brasília: CENAD, 2014.

CAMPOS-VARGAS, M.; TOSCANA-APARICIO, A.; ALANÍS, J. C. 2015. Riesgo socionaturales: vulnerabilidad socioeconómica, justicia ambiental y justicia espacial. Cuadernos de Geografia: Revista Colombiana de Geografía, Bogotá, Colombia, v.24, n.2, p.53-69, jul.-dic. del 2015.

https://doi.org/10.15446/rcdg.v24n2.50207

CPRM - Serviço Geológico do Brasil. Ministério de Minas e Energia. Mapas estaduais de geodiversidade: Ceará. Rio de Janeiro: CPRM. 2006a. Documento cartográfico em arquivo vetorial. Disponível em <http://geobank.sa.cprm.gov.br>. Acesso em: 14 jan. 2014.

Mapas estaduais de geodiversidade: Piauí. Rio de Janeiro: CPRM. 2006b. Documento cartográfico em arquivo vetorial. Disponível em <http://geobank.sa.cprm.gov.br>. Acesso em: 14 jan. 2014.

Mapa Geológico do Estado do Piauí. $2^{\text {a }}$ Versão. Teresina, 2006c.

CUNHA, L.; MENDES, J. M.; TAVARES, A.; FREIRIA, S. Construção de modelos de avaliação de vulnerabilidade social a riscos naturais e tecnológicos: o desafio das escalas. O processo de Bolonha e as reformas curriculares da geografia em Portugal. Presented at the. Coimbra, Portugal, 2011. https://doi.org/10.14195/978-989-26-0244-8_71

CUTTER, S. L. A ciência da vulnerabilidade: modelos, métodos e indicadores. Revista Crítica de Ciências Sociais [Online], Coimbra, Portugal, v.93, 2011. https://doi.org/10.4000/rccs.165

The vulnerability of science and the science of vulnerability. Annals of the Association of American Geographer. n. 93, p.1-12, 2003. https://doi.org/10.1111/14678306.93101

FIELD, A. Descobrindo a estatística usando SPSS. Tradução: Lorí Viali. 2. ed. Porto 
Alegre: Artme, 2009.

FRAGOSO, M. L. C.; GEHLEN, V. R. F.; SILVA, T. A. S. A Condição das Mulheres Diante das Situações de Desastres Naturais. Revista Brasileira de Geografia Física, v.03, p.473487, 2012.

https://doi.org/10.26848/rbgf.v5i3.232839

IBGE - Instituto Brasileiro de Geografia e Estatística. Agregados por setores censitários dos resultados de universo. Censo 2010. Disponível em: $<$ http://www.ibge.gov.br/home/estatistica/popul acao/defaulttab_agregado.shtm>. Acesso em: 25 jun. 2018.

Malha municipal digital do Brasil: situação em 2015. Rio de Janeiro: IBGE, 2014. Disponível em: <ftp://geoftp.ibge.gov.br/malhas_digitais/>. Acesso em: 04 abr. 2016.

INDE - Infraestrutura Nacional de Dados Especiais. Mapa de Solos da Folha SB.24 Jaguaribe. Disponível em: <http://www.visualizador.inde.gov.br/>. 2014. Acesso em: 13 set. 2018.

LAVELL, A. Gestión Ambiental y Gestión del Riesgo de Desastre en el Contexto del Cambio Climático: Una Aproximación al Desarrollo de un Concepto y Definición Integral para Dirigir la Intervención a través de un Plan Nacional de Desarrollo. Departamento Nacional de Planeación-DNP. Subdirección de Desarrollo Ambiental Sostenible. 2010.

LIMA, P. H. G. Promoção Imobiliária em Teresina/PI: Uma análise do desenvolvimento da produção privada de habitações 1984/1999. 101f. Dissertação (Mestrado em Desenvolvimento Urbano). Universidade Federal de Pernambuco, Centro de Artes e Comunicação, Recife - PE, 2001.

MARCELINO, E. V. Desastres naturais e geotecnologias: conceitos básicos. São José dos Campos: INPE, 2008. 38p.

MARTINEZ, L.; FERREIRA, A. Análise de dados com SPSS: primeiros passos. Lisboa: Escolar editora, 2010.

MENDES, J.; TAVARES, A. O.; CUNHA, L.; FREIRIA, S. A vulnerabilidade social aos perigos naturais e tecnológicos em Portugal. Revista Crítica de Ciências Sociais, n.93, p.95-128, junho 2011. https://doi.org/10.4000/rces.90

NUNES, L. H. Urbanização e desastres naturais. - São Paulo: Oficina de Textos, 2015.

RAMOS, M. H. R. (org.). Metamorfoses sociais e políticas urbanas. Rio de Janeiro: DP\&A,
2003.

ROGERSON, P. A. Métodos estatísticos para geografia: um guia para o estudante. Tradução técnica: Paulo Fernando Braga Carvalho, José Irineu Rangel Rigotti. - 3. ed. Porto Alegre: Bookman, 2012.

SALES, M. C. L. Evolução dos estudos de desertificação no Nordeste brasileiro. Revista GEOUSP, Espaço e Tempo, São Paulo, SP, n.11, p.115-126, 2002.

SANTOS, F. A. Resiliência ambiental a secas e a inundações na Sub-bacia Hidrográfica do rio Piracuruca (CE-PI). 268p. Tese (Doutorado em Geografia) - Universidade Estadual do Ceará, Centro de Ciências e Tecnologia, Programa de Pós-Graduação em Geografia, Fortaleza, 2019.

SELA - Sistema Económico Latinoamericano y del Caribe. Lineamentos para la cooperación entre gobiernos y el sector privado en la reducción de riesgo de desastres. Enfoques, avances y retos. In: Seminario Regional "Cooperación entre gobiernos y sector privado para a reducción del riesgo de desastres en América Latina y el Caribe: Enfoques, avances y retos". SP/SRCGSPRRD/DT n ${ }^{\circ}$ 2-11. Ciudad de Panamá, Panamá. 2011.

USGS - United States Geological Service (Serviço Geológico dos Estados Unidos). Earth Explorer - Digital Elevation - SRTM 1 ArcSecond Global. 2017. Disponível em $<$ http://earthexplorer.usgs.gov/>. Acesso em: 23 nov. 2017. 